Bond University

Research Repository

\title{
Self-compassion in Relation to Alexithymia, Empathy, and Negative Mood in Young Adults
}

Lyvers, Michael; Randhawa, Ashveen; Thorberg, Fred Arne

Published in:

Mindfulness

DOI:

10.1007/s12671-020-01379-6

Licence:

Other

Link to output in Bond University research repository.

Recommended citation(APA):

Lyvers, M., Randhawa, A., \& Thorberg, F. A. (2020). Self-compassion in Relation to Alexithymia, Empathy, and Negative Mood in Young Adults. Mindfulness, 11(7), 1655-1665. https://doi.org/10.1007/s12671-020-01379-6

\footnotetext{
General rights

Copyright and moral rights for the publications made accessible in the public portal are retained by the authors and/or other copyright owners and it is a condition of accessing publications that users recognise and abide by the legal requirements associated with these rights.
}

For more information, or if you believe that this document breaches copyright, please contact the Bond University research repository coordinator. 
Self-Compassion in Relation to Alexithymia, Empathy, and Negative Mood in Young Adults

${ }^{1}$ Michael Lyvers, Ph.D.

${ }^{1}$ Ashveen Randhawa, Bachelor of Psychological Science (Honours)

${ }^{2}$ Fred Arne Thorberg, Ph.D.

${ }^{1}$ School of Psychology, Bond University, Gold Coast Qld Australia

${ }^{2}$ National Centre for Dual Diagnosis, Innlandet Hospital Trust, Brummundal, Norway

Corresponding author: Michael Lyvers, Associate Professor, School of Psychology, Bond

University, Gold Coast Qld 4229 Australia. Phone: +61755952565 Email: mlyvers@,bond.edu.au

ORCID ID: 0000-0002-8355-3182 
Self-Compassion in Relation to Alexithymia, Empathy, and Negative Mood in Young Adults 


\begin{abstract}
Objectives. Alexithymia, a trait defined by difficulties identifying and describing emotional feelings and overly concrete thinking, is a known risk factor for psychopathology. Given recent evidence that therapeutic constructs based on Buddhist concepts are positively related to emotional self-awareness and mental health, the present study examined the relationship between one such construct, self-compassion, and alexithymia as well as empathy and mood in a sample of young Australian adults. Methods. Participants were 253 young adults aged 18-30 years who were recruited from two Australian universities. They were administered validated measures of alexithymia, self-compassion, and empathy via a survey hosting website. Results. Relationships among variables were as expected: alexithymia was negatively correlated with self-compassion and empathy, and the latter two variables were positively correlated with each other. After controlling for relevant covariates, alexithymia was the strongest (negative) predictor of self-compassion in a hierarchical regression model. Both alexithymia and self-compassion explained variance in negative mood (depression, anxiety, stress) in a second regression. Of six subcomponents of selfcompassion, only self-judgement was significant. Conclusions. Further research is needed on alexithymia as a risk factor in young adults and the potential role of self-compassion in mitigating such risk.
\end{abstract}

Keywords: self-compassion; alexithymia; empathy; self-regulation; mindfulness 
Recently introducted approaches to psychotherapy, inspired by Buddhist meditation practices, have focused on cultivating mindfulness and self-compassion (Hayes \& Hofmann 2017; Öst, 2008), and emphasize awareness and self-regulation of emotions as essential aspects of psychological health (Hayes et al., 2006). Deficiencies of emotional awareness and self-regulation characterize the subclinical personality trait alexithymia (Velde et al., 2013), which is commonly elevated in clinical samples of depression or anxiety disordered clients (McGillivray et al., 2016; Onur et al., 2013; Panayiotou et al., 2015; Taylor et al., 1997) as well as in clients with alcohol or other substance use disorders (Cruise \& Becerra, 2018; Lyvers et al., 2014a; Thorberg et al., 2009; Thorberg et al., 2011b). As a relatively stable trait (Thorberg et al., 2016; Tolmunen et al., 2011), high alexithymia appears to be a significant risk factor for a variety of forms of psychopathology. Given recent evidence indicating that increases in self-compassion are associated with improvements in the mental health of young adults (Dundas et al., 2017), and that self-compassion is negatively related to difficulties with emotion regulation (Finlay-Jones et al., 2015), trait alexithymia is likely to show negative relationships with self-compassion in addition to psychological well-being.

Alexithymia is a multidimensional construct encompassing difficulties identifying and describing emotional feelings and a concrete thinking style (Bagby et al., 2020). The prevalence of high alexithymia within general community samples worldwide has been estimated to be around 10-15\% (e.g., Franz et al., 2008; Mattila et al., 2006), but substantially higher prevalence is reported for clinical samples. According to a recent Australian study, 12\%, 48.6\%, and 39.4\% of participants in a community sample had high, intermediate, and low levels of alexithymia, respectively, compared to $45.7 \%, 45 \%$, and $9.3 \%$ in a psychiatric sample (McGillivray et al., 2016). Interestingly, these authors reported that the association between alexithymia and psychological distress was similar for both psychiatric and community samples. The etiology of alexithymia remains unclear; its heritability is estimated at only around 30\% (Jorgenson et al., 2007), hence developmental influences are likely important. For example, childhood neglect or the absence of 
affiliative relationships in the early years may lead to developmental deficits of processing and labelling emotions (Aust et al., 2013; Evren et al., 2009; Fonagy \& Target, 2006; Lyvers et al., 2019; Mikulincer \& Shaver, 2007; Thorberg et al., 2011a).

Young adults between the ages of 18 to 30 years are at greater risk of developing mental health problems compared to older adults (Stallman, 2010) and also tend to show higher levels of alexithymia. Mason et al. (2005) reported that, based on the established cut-off score on the Toronto Alexithymia Scale (TAS-20; Bagby et al., 1994ab), the prevalence of high alexithymia in university students was $17.9 \%$ in Britain, $17.1 \%$ in France and $18.8 \%$ in Canada. This is potentially concerning, as high trait alexithymia is likely to put young adults at risk for various psychological disorders (Taylor et al., 1997). Further, those with higher levels of alexithymia report lower life satisfaction and have an increased risk of self-harm (Hintikka et al., 2004; McGillivray et al., 2016; Velde et al., 2013) compared to those with low levels of alexithymia. Highly alexithymic individuals tend not to seek support from others when they experience distress (Vanheule et al., 2007), presumably due to persistent interpersonal difficulties which may stem from deficient emotional empathy (Zackheim, 2007).

Empathy, like alexithymia, is a multidimensional construct entailing both cognitive and emotional elements; these include the capacity to take the perspectives of others, resonate with another person's feelings, and respond in a way that emotionally corresponds to what the other is feeling (Davis, 1980; Singer, 2006). Empathy deficits in alexithymia (Grynberg et al., 2010; Guttman \& Laporte, 2002; Moriguchi et al., 2007) have been linked to deficient ability to recognize and correctly label the emotional states of others (Lyvers et al., 2017, 2018), which seems to fit with the difficulties reported by highly alexithymic individuals in recognizing and labelling their own emotional states. Therapies and practices that promote self-awareness and compassion may thus have the potential to improve emotional awareness and empathy in those with high levels of alexithymia. 
Various studies have supported the potential of self-compassion to enhance awareness and regulation of emotional states (Bakker et al., 2019; Diedrich et al., 2014; Gilbert et al., 2011; MacBeth \& Gumley, 2012; Neff et al., 2007). Self-compassion, derived from Buddhist philosophy, can be understood as a healthy form of self-acceptance (Neff, 2004) that involves being understanding and kind to oneself rather than critical when experiencing perceived failure or suffering, while recognising that emotional pain and feelings of inadequacy and imperfection are part of the shared and inevitable human experience. Self-compassion also encompasses having a balanced awareness of one's emotional states such that negative feelings are neither exaggerated nor suppressed (Neff, 2003a). Neff (2011) describes self-compassion as an overall dimension that also includes sub-components. These components can be assessed across a continuum from selfkindness to self-judgement, common humanity to isolation, and mindfulness to over-identification. Self-compassion may be a substantial indicator of mental health; a meta-analysis concluded that higher levels of self-compassion were linked to lower levels of depression, anxiety, and stress (Macbeth \& Gumley, 2012). Self-compassion has been positively linked to life satisfaction, social connectedness, optimism, curiosity and exploration, with increased levels of self-compassion indicating improved psychological health over time (Neff et al., 2007). An intervention study by Dundas et al. (2017) found that even a short, two-week self-compassion training course increased perceived self-regulation and general mental health in university students, with changes persisting at six-month follow-up.

Although mindfulness is considered a subcomponent of self-compassion and within that context is understood as an ability to purposefully attend to and accept negative and uncomfortable present experiences (Beddoe \& Murphy, 2004), mindfulness as a general construct is defined as being purposefully attentive, accepting and open to all present moment experiences (Hayes et al., 2004). Mindful attention requires observation of thoughts and feelings without scrutiny or judgement (Segal et al., 2002), and to hold compassion for oneself it is necessary to be mindfully aware and connected to ongoing experiences and feelings even when these are unpleasant (Neff, 
2003a). Mindfulness has been reported to be inversely related to alexithymia (Lykins \& Baer, 2009; Lyvers et al., 2014b), and a mindfulness-based intervention was recently reported to reduce alexithymia (Norman et al., 2018). As alluded to above, although mindfulness and self-compassion are said to be linked, they are not the same. Mindfulness has a broad focus, referring to nonjudgemental, enhanced awareness of all pleasant or unpleasant experiences, including passing feelings and thoughts, sounds, sights and bodily sensations, whereas self-compassion involves understanding and responding to one's own suffering (Boellinghaus et al., 2014). Furthermore, selfcompassion may be a stronger predictor of psychological health than mindfulness (Rendon, 2006). The ability to engage in self-soothing, show kindness and help oneself to feel better when things go wrong can help reduce distress and improve coping skills and resilience (Neff, 2011). Selfcompassion can thus be expected to show a negative relationship with alexithymia, as was previously reported for mindfulness (Lyvers et al., 2013), given that mindful awareness of negative experiences and feelings is a requisite subcomponent of self-compassion.

Self-compassion is also often assumed to be linked with empathy, yet relevant research findings have been limited and somewhat mixed, perhaps due to variation in forms and definitions of empathy. Some research has supported a positive relationship between self-compassion and cognitive forms of empathy such as perspective taking (Birnie et al., 2010), whereas other studies have reported mixed results (Neff \& Pommier, 2013) or no relationship for emotional empathy (Wei et al., 2011). The inconsistencies in previous work may reflect the use of measures that defined empathy differently (Reniers et al., 2012). For example, the Balanced Emotional Empathy Scale (BEES; Mehrabian, 2000), used in Wei et al.'s (2011) study, focuses solely on emotional empathy and may thereby be limited in encapsulating all facets of empathy (Neumann et al., 2015). On the other hand, the Interpersonal Reactivity Index (IRI; Davis, 1983), used in the study by Guttman and Laporte (2002), may be too broad as it includes items that assess imagination and emotional selfcontrol (Baron-Cohen \& Wheelwright, 2004). A newer measure of empathy, the Toronto Empathy Questionnaire (TEQ; Spreng et al., 2009), has been claimed to encompass the essential facets of 
empathy via a short and homogenous scale, with a single robust factor structure, and thus may have some advantages over earlier empathy measures (Neumann et al., 2015; Spreng et al., 2009).

A prerequisite to empathy is the ability to recognize the mental and emotional states of others (Lyvers et al., 2018), with the human face playing a key role in the display of subjective states. Parker et al. (1993) reported that those with high levels of alexithymia were deficient in the ability to recognize facial expressions of 7 out of 9 basic emotions. Highly alexithymic individuals have been reported to make emotion recognition errors such as misidentifying positive emotions as negative ones (Prkachin et al., 2009). Such deficits may account for the low levels of empathy in those with high levels of alexithymia, as well as their interpersonal difficulties, which could plausibly result from their tendency to misidentify others' emotions and respond inappropriately. A recent study by Lyvers et al. (2018) found that deficient ability to recognize facial expressions of emotions - as measured by performance on the Reading the Mind in the Eyes Test (RMET; BaronCohen et al., 2001) - mediated the negative relationship between alexithymia and emotional empathy as measured by the corresponding IRI subscale.

The current study assessed self-compassion in relation to alexithymia, empathy (as measured by the single-factor TEQ), and psychological distress (depression, anxiety, stress) in a nonclinical sample of young adults. As McGillivray et al. (2016) found that the association between alexithymia and psychological distress was similar for both psychiatric and community samples, the use of a community sample was deemed appropriate for present purposes. A positive relationship was anticipated between self-compassion and empathy, and both of those variables were expected to show negative relationships with alexithymia. In hierarchical regression models, alexithymia and empathy were predicted to account for significant variance in self-compassion, and both alexithymia and self-compassion were predicted to account for significant variance in negative mood (depression, anxiety, stress) as an indicator of psychological distress.

\section{Method}

\section{Participants}


There were initially 267 young adults recruited for this study from two universities in southeast Queensland, Australia, via campus-wide email and online notices that briefly described the project and requested participants aged 18-30 years to complete an online survey. After removing 11 multivariate outliers and 3 volunteers who reported having suffered a brain injury, the final sample consisted of 253 young adults (42 males, 208 females) aged 18-30 years $(M=21.57$, $S D=3.40)$. Most $(246 ; 97 \%)$ were current students. A slight majority of participants $(145 ; 57 \%)$ reported that grade 12 was their highest completed education level, whereas 3 participants (1.2\%) had not completed grade 12; 86 (34\%) had completed an undergraduate degree; and $19(7.5 \%)$ had completed a postgraduate degree. Most participants $(182 ; 72 \%)$ reported that they drank alcoholic beverages. Relatively few $(25 ; 10 \%)$ currently used illicit drugs, whereas 48 (19\%) reported that they were currently taking medication for a psychiatric or neurological condition. A majority of participants indicated their country of origin as Australia $(170 ; 67 \%)$, followed by the USA (20; $8 \%$ ), with the remaining origins spread fairly evenly among 38 other countries worldwide. The incentive offered for participation was either a credit point toward an undergraduate psychology subject (only 38 students chose this) or entering a random draw for one of two $\$ 50$ gift vouchers.

\section{Procedure}

Approval was obtained from the ethics committees of both universities prior to conducting the study. Participants were recruited via campus-wide email at one university and from the student research participation recruitment system at the other. In both cases a brief explanatory statement describing the research and the anonymous and voluntary nature of participation was followed by a link to the online survey. The online questionnaire battery, consisting of the demographic questionnaire and measures of self-compassion, alexithymia, empathy, and negative mood, was created using the online survey hosting company Qualtrics. Once participants clicked on the link, they were directed to a more detailed explanatory statement, at the bottom of which was the word "proceed"; by clicking on that, participants gave their consent to participate. Once participants had given consent, they completed the demographic questions followed by the measures presented in a 
uniquely randomized order per participant. Participants had to respond to all items on a page before they could continue to the next set of items. Upon survey completion, participants were provided with a "thank you" page as appreciation and were reminded to email the researcher a screenshot of this page to qualify for their incentive. After completion of data collection, a random draw resulted in two winners receiving their electronic gift vouchers via email.

\section{Measures}

Demographics. A 12-item questionnaire requested information on participants' age, gender, country of origin, English proficiency, student status, highest level of education completed, and whether or not they drank alcohol, used illicit drugs, were currently on medication for a psychiatric or neurological condition, and/or if they had ever suffered a brain injury. Some of these questions checked the inclusion criteria (18-30 years old, English-proficient, no history of brain injury) whereas others provided data on potential confounding variables for control purposes.

Self-Compassion Scale (SCS; Neff, 2003b, 2015). The SCS is a 26-item self-report questionnaire designed to assess the degree to which individuals have a compassionate orientation to themselves during times of difficulty or challenge. The SCS has six subscales: self-kindness, common humanity, mindfulness, self-judgement, isolation and over-identification. The first three are "positive" subscales, whereas the latter three subscales measure negative components of selfcompassion and thus require reverse scoring in calculating an overall SCS score. Responses to each item are implemented via a five-point Likert scale ranging from 1 (almost never) to 5 (almost always). Neff et al. (2017) suggested that although the total mean score provides a psychometrically sound overall index of self-compassion, analyses using the mean scores for each of the six subscales are likely to provide more detailed information. Both approaches were used in the present study. Neff et al.'s (2017) findings did not support treating the positive subscales as one factor and the negative subscales as another factor. In the present sample the Cronbach's alpha index of internal consistency reliability for the total mean SCS score was excellent, $\alpha=.94$. 
Toronto Alexithymia Scale (TAS-20; Bagby et al., 1994ab). The TAS-20 is a 20 -item selfreport measure assessing levels of alexithymia via three subscales: difficulty describing feelings, difficulty identifying feelings, and externally oriented thinking. Item responses are via a five-point Likert scale ranging from 1 (strongly disagree) to 5 (strongly agree). Five negatively worded items are reverse scored. The total alexithymia score is the sum of responses to all 20 items, which was used in the present study. Possible total alexithymia scores range from 20 to 100, with higher scores indicating higher levels of alexithymia. Scores of 61 or higher suggest high alexithymia (Bagby et al., 1994b), however the TAS-20 was used in the present study as a continuous measure of this trait. In the present sample the TAS-20 showed good internal consistency, $\alpha=.84$.

Toronto Empathy Questionnaire (TEQ; Spreng et al., 2009). The TEQ is a 16-item selfreport questionnaire measuring empathy. There are an equal number of positively and negatively worded items, with the latter items reverse scored. Item responses are implemented on a five-point Likert scale ranging from 0 (never) to 4 (always). The sum of all responses provides a total empathy score, with higher scores indicating higher levels of empathy. TEQ items were developed based on factor analysis of 142 items from 11 different empathy and empathy-related scales, with an additional 36 items that specifically described individuals with impaired empathic abilities resulting from neurological or psychiatric diseases. An exploratory factor analysis eliminated items demonstrating low item-remainder coefficients, items that did not improve the internal reliability of the scale, and items with lower factor loadings, resulting in 16 retained items. In the present sample the TEQ showed good internal consistency, $\alpha=.87$.

Depression Anxiety Stress Scales 21 (DASS-21; Lovibond \& Lovibond, 1995). The DASS-21 is a 21-item self-report instrument comprised of three scales measuring the negative emotional symptoms of depression, anxiety, and stress. Respondents are asked to rate items by the degree to which they had experienced each symptom over the past week. Each scale has seven items that are measured on a four-point Likert scale ranging from 0 (did not apply to me at all) to 3 (applied to me very much, or most of the time). To obtain scale scores, the scores for all items within 
each scale are summed; scores of all three scales can be summed to provide an overall index of negative mood. Total scores can range from 0 to 84 , with higher scores reflecting more negative affect. In the present sample the total DASS-21 showed excellent internal consistency reliability, $\alpha$ $=.94$.

\section{Data Analyses}

The present study used a hierarchical regression model to assess the contributions of alexithymia and empathy to variance in self-compassion after controlling for relevant covariates. A second hierarchical regression model was used to assess the contributions of alexithymia and selfcompassion to variance in psychological distress (as indicated by the DASS-21 negative mood index) after controlling for relevant covariates. A variation on the latter regression used the six SCS subscales instead of the total mean score to assess the potential role of subcomponents of selfcompassion in psychological distress.

\section{Results}

\section{Preliminary Analyses}

The dataset was examined for potential confounding variables to potentially include as covariates in the regression models. Multivariate comparison of current illicit drug users to nonusers showed no significant group differences on the variables of interest (i.e., self-compassion, empathy, alexithymia, and negative mood) according to Pillai's Trace, $F(5,247)=.59, p=.71$. Similarly, Pillai's Trace indicated no significant group differences between those who consume alcoholic beverages and those who do not, $F(5,247)=1.49, p=.19$. Illicit drug use and alcohol use were thus not included as covariates in the regressions. On the other hand, Pillai's Trace indicated significant group differences between those currently taking medication for a psychiatric or neurological disorder and those not on such medication, $F(5,247)=6.48, p<.0001$. Univariate group differences were significant for self-compassion, $F(1,251)=13.41, p<.0001$, and negative mood, $F(1,251)=23.21, p<.0001$. Those taking medication scored significantly lower on selfcompassion $(M=2.37, S D=.76)$ than those not on medication $(M=2.82, S D=.75)$. Those taking 
medication also scored significantly higher on negative $\operatorname{mood}(M=28.83, S D=15.23)$ than those not on medication $(M=18.33, S D=13.20)$. Comparison of men and women on the variables of interest also revealed a significant multivariate effect according to Pillai's Trace, $F(10,494)=2.58$, $p<.0001$. There was only one univariate group difference, such that women $(M=49.61, S D=$ 7.06) scored significantly higher than men $(M=44.12, S D=11.65)$ on empathy, $F(2,250)=8.26, p$ $<.0001$. Gender and medication status were thus included as covariates in the regression analyses.

Bivariate correlations among the variables of interest as well as two potential covariates, age and education, are shown in Table 1 . As can be seen in the table, age was not correlated with any of the variables of interest, whereas education level was; the latter was thus another covariate in the regressions. The total SCS index of self-compassion was positively correlated with education and the TEQ measure of empathy, and negatively correlated with TAS-20 alexithymia scores and the total DASS-21 negative mood index as per predictions. As expected, alexithymia was negatively correlated with empathy, and positively correlated with negative mood.

\section{Alexithymia and Empathy as Predictors of Self-Compassion}

A hierarchical linear regression was conducted to explore the relationships of empathy and alexithymia with self-compassion after controlling for potential influences of gender, education and medication status. At step 1, the covariates education, gender, and medication status accounted for $10.6 \%$ of variance in self-compassion and the model was significant, $F(3,249)=9.87, p<.0001$. Education and medication status were significant, with the former a positive predictor and the latter a negative predictor. At step 2, empathy was entered in the model and explained a small but significant $1.6 \%$ of additional variance, $F$ change $(1,248)=4.57, p=.03$. Empathy was a significant positive predictor, as expected, and education and medication status remained significant as before. In the third and final step, alexithymia was entered and accounted for a significant $21.7 \%$ of additional variance, Fchange $(1,247)=81.12, p<.0001$. The final model explained $34 \%$ of the variance in self-compassion scores. As predicted, alexithymia was a significant negative predictor of self-compassion and by far the strongest predictor overall, followed by medication status and 
education; empathy was no longer significant at this step. Table 2 presents the relevant regression statistics.

\section{Alexithymia and Self-Compassion as Predictors of Negative Mood}

A second hierarchical regression was conducted to assess the relative contributions of alexithymia and self-compassion to negative mood (as an index of psychological distress) after controlling for gender, education and medication status. The same covariates as in the previous regression were entered in step 1, accounting for a significant $10.7 \%$ of variance in negative mood, $F(3,249)=9.91, p<.0001$; medication status was a significant positive predictor whereas education was a significant negative predictor. Entry of alexithymia at step 2 explained a significant $21.5 \%$ of additional variance, Fchange $(1,248)=78.75, p<.0001$. As expected, alexithymia was a significant positive predictor, with medication status remaining significant at this step. At the third and final step self-compassion was entered, accounting for a significant $6.8 \%$ of additional variance, Fchange $(1,247)=27.74, p<.0001$. The final model explained $41 \%$ of the variance in negative mood. Table 3 presents the relevant regression statistics. Self-compassion was a significant negative predictor and was the strongest predictor in the model, followed by alexithymia and medication status as positive predictors.

\section{SCS Subscales in Relation to Alexithymia, Empathy, and Negative Mood}

Bivariate correlations of the six SCS subscales with the other variables of interest are presented in Table 4. As can be seen in the table, both alexithymia and the negative mood index were significantly negatively correlated with all three positive SCS subscales (self-kindness, common humanity, mindfulness) and significantly positively correlated with all three negative SCS subscales (self-judgement, isolation, overidentification). Empathy was significantly positively correlated with all three positive subscales but was not correlated with any of the negative subscales. When the same regression analysis on negative mood was conducted as before, but with the six SCS subscale mean scores as separate predictors instead of the total SCS mean score at the final step, the only subscale to predict unique variance was the self-judgement subscale. Self- 
judgement was the strongest predictor of negative mood in the final model, followed by alexithymia and medication status (see Table 5). The final model explained $47 \%$ of the variance in negative mood.

\section{Discussion}

Present findings were generally consistent with expectations. Correlations were in predicted directions, such that total SCS self-compassion was positively correlated with the TEQ index of empathy and negatively correlated with both alexithymia and the DASS-21 index of psychological distress. Further, both alexithymia and psychological distress were significantly negatively correlated with the three positive SCS subscales (self-kindness, common humanity, mindfulness), and positively correlated with the three negative SCS subscales (self-judgement, isolation, overidentification), whereas empathy was significantly correlated with the positive subscales but not the negative ones. In addition, based on previous research (Guttman \& Laporte, 2002; Lyvers et al., 2017, 2018; Prkachin et al., 2009), alexithymia was expected to be negatively correlated with empathy, which was supported. However, in the hierarchical regression on self-compassion, although empathy did account for significant variance in self-compassion as predicted, this was no longer the case once alexithymia was entered into the model. Alexithymia was by far the strongest (negative) predictor of self-compassion in the model. Present results thus support the hypothesis that alexithymia is not only associated with empathy deficits and proneness to psychological distress, but also with low levels of self-compassion. These findings are in line with previous reports that higher levels of self-compassion were linked to lower levels of negative moods (e.g., Bakker et al., 2019; Macbeth \& Gumley, 2012) as well as improved psychological health (e.g., Krieger et al., 2016; Neff, 2003a). The present results may suggest that in those with high levels of alexithymia, deficient self-compassion may contribute to the negative mood proneness commonly associated with this trait.

In the hierarchical regression on negative mood, both alexithymia and self-compassion were significant predictors (as expected) after controlling for relevant covariates; however, the 
contribution of alexithymia decreased after self-compassion was entered into the model, with selfcompassion the strongest (negative) predictor. When this regression was conducted using the six SCS subscales instead of the total mean score at the final step, only self-judgement accounted for significant variance in negative mood after controlling for alexithymia and covariates, with selfjudgement the strongest predictor in the model. Alexithymia and self-judgement were highly significant predictors in the final regression model, which accounted for $47 \%$ of variance in negative mood.

A plausible interpretation of the present findings is that in a highly alexithymic individual, the constricted awareness of emotions of self and others is accompanied by an intolerant and constricted attitude toward their own personal limitations and inadequacies, a failure to see themselves as part of the bigger picture of the human condition. This in turn may help to explain why alexithymia is so often associated with negative mood states such as depression, anxiety and stress, as well as maladaptive coping strategies such as problem drinking. Recent trials indicate that expanding awareness and understanding of the self and its place in the world through meditation practices and related therapies promoting self-compassion (e.g., Dundas et al., 2017; Gilbert \& Proctor, 2006; MacBeth \& Gumley, 2012), or more controversially via administration of psychedelic drugs such as psilocybin in a supportive context (Carhart-Harris et al., 2017; Moreno et al., 2005; Ross et al., 2016), may provide lasting mental health benefits for some people. Highly alexithymic individuals might especially benefit from therapies or practices that promote selfcompassion, although such speculation goes well beyond the present findings. Interestingly, present results showed substantial correlations in expected directions between alexithymia and all six subcomponents of self-compassion as operationally defined by the SCS.

Early attachment relationships are likely to have a substantial influence on strategies that adults use to regulate their emotions (Lyvers et al., 2019; Neff \& McGhee, 2010; Thorberg et al., 2011a). Inconsistent parenting and insecure attachments may lead to the development of a negative view of self and frequent self-criticism, as well as the affect regulation difficulties that characterize 
alexithymia (Wei et al., 2011). Such individuals can be expected to lack the requisite resources within themselves to cultivate and foster self-compassion, perhaps accounting for the negative relationship between alexithymia and self-compassion found in the current sample. The present findings also appear consistent with previous reports of a negative association between mindfulness and alexithymia (Lykins \& Baer, 2009; Lyvers et al., 2014b) given the importance of mindful awareness of one's own suffering as a subcomponent of self-compassion (Neff, 2003a; Segal et al., 2002). The potential role of mindfulness, as broadly conceived, in the relationship between alexithymia and self-compassion would be an interesting topic for future work.

\section{Limitations and Future Research}

The current study had a number of limitations that must be considered. Firstly, the majority of participants were female (although gender was controlled for as a covariate in the regressions) and most were young adults at university, limiting the generalizability of the findings to other age groups or young adults not at university. Future studies on the issues examined in the present investigation are thus advised to recruit more representative samples. Nevertheless, the predicted relationship between alexithymia and self-compassion was supported, consistent with current theoretical interpretations of these constructs. Secondly, there has been some controversy over the measurement of self-compassion using the SCS (Neff, 2003b). One study applying Confirmatory Factor Analysis found no support for the six-factor model, but supported a two factor model consisting of the negative and positive items of the SCS (Lopez et al., 2015), with the authors arguing that based on these two factors a distinction should be made between self-compassion and self-criticism. Other researchers have suggested that the moderate to strong relationships of the negative items with mental health problems may lead to an inflated association with psychopathology (Muris \& Petrocchi, 2016). Moreover, as pointed out by Gilbert et al. (2017), when using the combination of positive and negative items as a single measure or construct, one can be high or low on both and still get the same score. Thirdly, the current study used a cross-sectional design, which restricts interpretation of the findings given that correlational studies cannot provide 
clear evidence of causal relationships. On the other hand, when a new area of investigation surfaces, cross-sectional data are often obtained first to support the proposed theoretical associations before decisions can be made to invest resources into more effortful, expensive and laborious longitudinal and intervention studies. Thus, a strength of the current study is that its findings can serve as a basis for further research of a more ambitious nature. Finally, as the current study relied on self-report indices of the relevant constructs, participants' responses were susceptible to common method bias. Future research on these issues may thus benefit from a multi-trait multi-method approach (Bagozzi \& Yi, 1993).

The negative relationship between alexithymia and self-compassion indicated by the present results is in line with previous evidence on the different coping and emotion regulation strategies used by highly alexithymic individuals compared to those characterized by self-compassion. For example, individuals with high alexithymia who consume alcoholic beverages often drink to cope with anxiety and stress, a maladaptive coping strategy that increases risk of problematic drinking (Lyvers et al., 2014c). Low self-compassion has been reported in alcohol dependence, and an increase in self-compassion over time was reportedly associated with more adaptive coping strategies and reduced drinking (Brooks et al., 2012). Future investigations might examine the potential role of deficient self-compassion in the relationship between alexithymia and risky or problematic drinking, given the prevalence of high alexithymia in clinical samples of clients undergoing treatment for alcohol use disorders (Cruise \& Becerra, 2018; Thorberg et al., 2009).

Future research endeavours in this area should note that Neff's (2003) definition of selfcompassion is somewhat different from other definitions of compassion. For example, in Gilbert's work compassion is defined as "the sensitivity to suffering in self and others, with a commitment to try to alleviate and prevent it" (Gilbert, 2014, p. 14). According to Gilbert (2009), compassion includes 12 competencies where the first six are related to the detection of suffering/distress; these include sensitivity, sympathy, distress tolerance, non-judgement, care for well-being, and empathy. The second set of six competencies are related to compassionate action; these include imagery, 
sensory, reasoning, attention, feeling, and behavioural competencies (Gilbert, 2009). As empathy within such a framework is a competency of compassion and can be used for compassionate motivation as well as other types of motivations (Gilbert, 2010), future research may benefit from including other measures (e.g., the Compassionate Engagement and Action Scales for self and others; Gilbert et al., 2017) to assess compassion in a more comprehensive way. Such a multifaceted approach could help improve our understanding of compassion for self and others in relation to alexithymia, empathy, and psychological distress.

Conflict of Interest: The authors declare that they have no conflict of interest.

Ethics Approval: This research was approved by the Bond University Human Research Ethics Committee and the Griffith University Human Research Ethics Committee. The research was performed in accordance with the ethical standards as laid down in the 1964 Declaration of Helsinki and its later amendments.

Consent to Participate: Informed consent was obtained from all individual participants included in the study.

Author Contributions: ML designed and executed the study, conducted data analyses, and wrote the manuscript. AR assisted with the design of the study, collected the data and assisted with the data analyses and writing. FT collaborated in the writing and editing of the final manuscript. 


\section{References}

Aust, S., Härtwig, E. A., Heuser, I., \& Bajbouj, M. (2013). The role of early emotional neglect in alexithymia. Psychological Trauma: Theory, Research, Practice, and Policy, 5, 225-232. doi:10.1037/a0027314

Bagby, R. M., Parker, J. D. A., \& Taylor, G. J. (1994a). The twenty-item Toronto Alexithymia Scale-I: Item selection and cross-validation of the factor structure. Journal of Psychosomatic Research, 38, 23-32. doi:10.1016/0022 -3999(94)90005-1

Bagby, R. M., Parker, J. D. A., \& Taylor, G. J. (2020). Twenty-five years with the 20-item Toronto Alexithymia Scale. Journal of Psychosomatic Research, in press. doi: 10.1016/j.jpsychores.2020.109940

Bagby, R., Taylor, G. J., \& Parker, J. D. (1994b). The twenty-item Toronto Alexithymia scale-II. Convergent, discriminant, and concurrent validity. Journal of Psychosomatic Research, 38, 33-40. doi:10.1016/0022-3999(94)90006-х

Bagozzi, R. P., \& Yi, Y. (1993). Multitrait-multimethod matrices in consumer research: Critique and new developments. Journal of Consumer Psychology, 2, 143-170. doi: 10.1016/S10577408(08)80022-8

Bakker, A.M., Cox, D.W., Hubley, A.M., \& Owens, R.L. (2019). Emotion regulation as a mediator of self-compassion and depressive symptoms in recurrent depression. Mindfulness, 10, 11691180. doi:10.1007/s12671-018-1072-3

Baron-Cohen, S., \& Wheelwright, S. (2004). The empathy quotient: An investigation of adults with Asperger syndrome or high functioning autism, and normal sex differences. Journal of Autism and Developmental Disorders, 34, 163-175. doi:

10.1023/B:JADD.0000022607.19833.00

Baron-Cohen, S., Wheelwright, S., Hill, J., Raste, Y., \& Plumb, I. (2001). The "Reading the Mind in the Eyes" test revised version: A study with normal adults, and adults with Asperger 
syndrome or high-functioning autism. Journal of Child Psychology and Psychiatry, 42, 241251. doi: $10.1017 / \mathrm{S} 0021963001006643$

Beddoe, A.E., \& Murphy, S.O. (2004). Does mindfulness decrease stress and foster empathy among nursing students? Journal of Nursing Education, 43, 305-312. doi: 10.3928/0148483420040701-07

Birnie, K., Speca, M., \& Carlson, L. E. (2010). Exploring self-compassion and empathy in the context of mindfulness-based stress reduction (MBSR). Stress and Health, 26, 359-371. doi:10.1002/smi.1305

Boellinghaus, I., Jones, F. W., \& Hutton, J. (2014). The role of mindfulness and loving-kindness meditation in cultivating self-compassion and other-focused concern in health care professionals. Mindfulness, 5, 129-138. doi:10.1007/s12671-012-0158-6.

Brooks, M., Kay-Lambkin, F., Bowman, J., \& Childs, S. (2012). Self-compassion amongst clients with problematic alcohol use. Mindfulness, 3, 308-317. doi:10.1007/s12671-012-0106-5

Carhart-Harris, R. L., Bolstridge, M., Day, C. J., Rucker, J., Watts, R., Erritzoe, D. E., \& ... Nutt, D. J. (2018). Psilocybin with psychological support for treatment-resistant depression: Sixmonth follow-up. Psychopharmacology, 235, 399-408. doi: 10.1007/s00213-017-4771-x

Cruise, K., \& Becerra, R. (2018). Alexithymia and problematic alcohol use: A critical update. Addictive Behaviors, 77, 232-246. doi: 10.1016/j.addbeh.2017.09.025

Davis, M. H. (1980). A multidimensional approach to individual differences in empathy. JSAS Catalogue of Selected Documents in Psychology, 44, 113-126. doi: 10.1037/00223514.44.1.113

Davis, M. H. (1983). Measuring individual-differences in empathy - Evidence for a multidimensional approach. Journal of Personality and Social Psychology, 44, 113-126. doi: $10.1037 / 0022-3514.44 .1 .113$ 
Diedrich, A., Grant, M., Hofmann, S. G., Hiller, W., \& Berking, M. (2014). Self-compassion as an emotion regulation strategy in major depressive disorder. Behaviour Research and Therapy, 58, 43-51. doi: 10.1016/j.brat.2014.05.006

Dundas, I., Binder, P., Hansen, T. G., \& Stige, S. H. (2017). Does a short self-compassion intervention for students increase healthy self-regulation? A randomized control trial. Scandinavian Journal of Psychology, 58, 443-450. doi:10.1111/sjop.12385

Evren, C., Evren, B., Dalbudak, E., Ozcelik, C., \& Oncu, F. (2009). Childhood abuse and neglect as a risk factor for alexithymia in adult male substance dependent inpatients. Journal of Psychoactive Drugs, 41, 85-92. doi:10.1080/ 02791072.2009.10400677

Finlay-Jones, A. L., Rees, C. S., \& Kane, R. T. (2015). Self-compassion, emotion regulation and stress among Australian psychologists: Testing an emotion regulation model of selfcompassion using structural equation modeling. PLoS One, 10(7), e0133481. doi: 10.1371/journal.pone.0133481.

Fonagy, P., \& Target, M. (2006). The mentalization-focused approach to self-pathology. Journal of Personality Disorders, 20, 544-576. doi: 10.1002/9780470712986.ch3

Franz, M., Popp, K., Schaefer, R., Sitte, W., Schneider, C., Hardt, J., . . Braeler, E. (2008). Alexithymia in the German general population. Social Psychiatry and Psychiatric Epidemiology, 43, 54-62. doi: 10.1007/s00127-007-0265-1

Gilbert, P. (2009). The compassionate mind: A new approach to the challenge of life. London: Constable \& Robinson.

Gilbert, P. (2010). Compassion focused therapy. London: Routledge.

Gilbert, P. (2014). The origins and nature of compassion focused therapy. British Journal of Clinical Psychology, 53, 6-41. doi: 10.1111/bjc. 12043.

Gilbert, P., Catarino, F., Duarte, C., Matos, M., Kolts, R., Stubbs, J.,...Basran, J. (2017). The development of compassionate engagement and action scales for self and others. Journal of Compassionate Healthcare, 4:4. doi: 10.1186/s40639-017-0033-3 
Gilbert, P., McEwan, K., Gibbons, L., Chotai, S., Duarte, J., \& Matos, M. (2011). Fears of compassion and happiness in relation to alexithymia, mindfulness, and selfcriticism. Psychology and Psychotherapy: Theory, Research and Practice, 85, 374-390. doi: 10.1111/j.2044-8341.2011.02046.x

Grynberg, D., Luminet, O., Corneille, O., Grèzes, J., \& Berthoz, S. (2010). Alexithymia in the interpersonal domain: A general deficit of empathy? Personality and Individual Differences, 49, 845-850. doi: 10.1016/j.paid.2010.07.013

Guttman, H., \& Laporte, L. (2002). Alexithymia, empathy, and psychological symptoms in a family context. Comprehensive Psychiatry, 43, 448-455. doi:10.1053/comp.2002.35905

Hayes, S. C., \& Hofmann, S. G. (2017). The third wave of cognitive behavioral therapy and the rise of process-based care. World Psychiatry, 16, 245-246. doi:10.1002/wps.20442

Hayes, S. C., Follette, V. M., \& Linehan, M. N. (2004). Mindfulness and acceptance: Expanding the cognitive behavioural tradition. New York: Guilford.

Hayes, S. C., Luoma, J. B., Bond, F. W., Masuda, A., \& Lillis, J. (2006). Acceptance and commitment therapy: Model, processes and outcomes. Behaviour Research and Therapy, 44, 1-25. doi: 10.1016/j.brat.2005.06.006

Hintikka, J., Honkalampi, K., Koivumaa-Honkanen, H., Antikainen, R., Tanskanen, A., Haatainen, K., \& Viinamäki, H. (2004). Alexithymia and suicidal ideation: A 12-month follow-up study in a general population. Comprehensive Psychiatry, 45, 340-345. doi:

10.1016/j.comppsych.2004.06.008

Krieger, T., Berger, T., \& Holtforth, M. (2016). The relationship of self-compassion and depression: Cross-lagged panel analyses in depressed patients after outpatient therapy. Journal of Affective Disorders, 202, 39-45. doi: 10.1016/j.jad.2016.05.032.

Lopez, A., Sanderman. R., Smink, A., Zhang, Y., van Sonderen, E., Ranchor, A., Schroevers, M.J., (2015). A reconsideration of the Self-Compassion Scale's total score: Self-compassion versus self-criticism. PLoS One. 10(7), e0132940. doi:10.1371/journal.pone.0132940 
Lovibond, S.H. \& Lovibond, P.F. (1995). Manual for the Depression Anxiety Stress Scales (2nd. Ed.). Sydney: Psychology Foundation.

Lykins, E. L. B., \& Baer, R. A. (2009). Psychological functioning in a sample of long-term practitioners of mindfulness meditation. Journal of Cognitive Psychotherapy, 23, 226-241. doi: http://dx.doi.org/10.1891/0889-8391.23.3.226

Lyvers, M., Hinton, R., Gotsis, S., Roddy, M., Edwards, E., \& Thorberg, F.A. (2014a). Traits linked to executive and reward systems functioning in clients undergoing residential treatment for substance dependence. Personality \& Individual Differences, 70, 194-199. doi: 10.1016/j.paid.2014.07.004

Lyvers, M., Kohlsdorf, S.M., Edwards, M.S., \& Thorberg, F.A. (2017). Alexithymia and mood: Recognition of emotion in self and others. American Journal of Psychology, 130, 83-92. doi: 10.5406/amerjpsyc.130.1.0083

Lyvers, M., Makin, C., Toms, E., Thorberg, F.A., \& Samios, C. (2014b). Trait mindfulness in relation to alexithymia, emotion regulation, mood and everyday executive functioning. Mindfulness, 5, 619-625. doi: 10.1007/s12671-013-0213-y5

Lyvers, M., Mayer, K., Needham, K., \& Thorberg, F.A. (2019). Parental bonding, adult attachment, and theory of mind: A developmental model of alexithymia and alcohol-related risk. Journal of Clinical Psychology. Early online: https://doi.org/10.1002/jclp.22772

Lyvers, M., McCann, K., Coundouris, S., Edwards, M. S., \& Thorberg, F. A. (2018). Alexithymia in relation to alcohol use, emotion recognition, and empathy: The role of externally oriented thinking. American Journal of Psychology, 131, 41. doi:10.5406/amerjpsyc.131.1.0041

Lyvers, M., Simons, O., Hayes, A., \& Thorberg, F. A. (2014c). Drinking motives, alcohol expectancies and alexithymia in young adult social drinkers. Journal of Substance Use, 19, 44-47. http://dx.doi.org/10.3109/14659891.2012.734538. 
Macbeth, A., \& Gumley, A. (2012). Exploring self-compassion in a meta-analysis of the association between self-compassion and psychopathology. Clinical Psychology Review, 32, 545-552. doi: 10.1016/j.cpr.2012.06.003

Mason, O., Tyson, M., Jones, C., \& Potts, S. (2005). Alexithymia: Its prevalence and correlates in a British undergraduate sample. Psychology and Psychotherapy: Theory, Research and Practice, 78, 113-125. doi: 10.1348/147608304X21374

Mattila, A. K., Salminen, J. K., Nummi, T., \& Joukamaa, M. (2006). Age is strongly associated with alexithymia in the general population. Journal of Psychosomatic Research, 61, 629-635. doi:10.1016/j.jpsychores.2006.04.013

McGillivray, L., Becerra, R., \& Harms, C. (2016). Prevalence and demographic correlates of alexithymia: A comparison between Australian psychiatric and community samples. Journal of Clinical Psychology, 73, 76-87. doi:10.1002/jclp.22314

Mehrabian, A. (2000). Manual for the Balanced Emotional Empathy Scale (BEES). Available from Albert Mehrabian; 1130 Alta Mesa Road, Monterey, CA, USA 93940.

Mikulincer, M., \& Shaver, P. R. (2007). Attachment in adulthood: Structure, dynamics and change. New York: Guilford.

Moreno, F.A., Wiegand, C.B., Taitano, E.K., \& Delgado, P.L. (2005). Safety, tolerability, and efficacy of psilocybin in 9 patients with obsessive-compulsive disorder. Journal of Clinical Psychiatry, 67, 1735-1740. doi: 10.4088/JCP.v67n1110

Moriguchi, Y., Decety, J., Ohnishi, T., Maeda, M., Mori, T., Nemoto, K., et al. (2007). Empathy and judging other's pain: An fMRI study of alexithymia. Cerebral Cortex, 17, 2223-2234. doi: 10.1093/cercor/bhl130

Muris, P., \& Petrocchi, N. (2016). Protection or vulnerability? A meta-analysis of the relations between the positive and negative components of self-compassion and psychopathology. Clinical Psychology and Psychotherapy (advanced online). doi: 10.1002/cpp.2005 
Neff, K. D. (2003a). Self-compassion: An alternative conceptualization of a healthy attitude toward oneself. Self and Identity, 2, 85-102. doi: 10.1080/15298860309032

Neff, K. D. (2003b). Development and validation of a scale to measure self-compassion. Self and Identity, 2, 223-250. doi: 10.1080/15298860309027

Neff, K. (2004). Self-compassion and psychological well-being. Constructivism in the Human Sciences, 9, 27-37.

Neff, K. (2008). Self-compassion: Moving beyond the pitfalls of a separate self-concept. In H. A. Wayment \& J. J. Bauer (Eds.), Decade of behavior. Transcending self-interest: Psychological explorations of the quiet ego (pp. 95-105). Washington, DC: American Psychological Association. doi: 10.1037/11771-009

Neff, K. (2011). Self-compassion. The proven power of being kind to yourself. New York: Harper Collins.

Neff, K. D. (2015). The Self-Compassion Scale is a valid and theoretically coherent measure of self-compassion. Mindfulness, 7, 264-274. doi:10.1007/s12671-015-0479-3

Neff, K. D., \& McGhee, P. (2010). Self-compassion and psychological resilience among adolescents and young adults. Self and Identity, 9, 225-240. doi: $10.1080 / 15298860902979307$

Neff, K. D., \& Pommier, E. (2013). The relationship between self- compassion and other-focused concern among college undergraduates, community adults, and practicing meditators. Self and Identity, 12, 160-176. doi: 10.1080/15298868.2011.649546

Neff, K. D., Rude, S. S., \& Kirkpatrick, K. L. (2007). An examination of self-compassion in relation to positive psychological functioning and personality traits. Journal of Research in Personality, 41, 908-916. doi: 10.1016/j.jrp.2006.08.002

Neff, K.D., Whittaker, T.A., \& Karl, A. (2017). Examining the factor structure of the SelfCompassion Scale in four distinct populations: Is the use of a total scale score justified? Journal of Personality Assessment, 99, 596-607. doi:10.1080/00223891.2016.1269334 
Neumann, D. L., Chan, R. C., Boyle, G. J., Wang, Y., \& Westbury, H. R. (2015). Measures of empathy: Self-report, behavioral, and neuroscientific approaches. In G. J. Boyle, D. H. Saklofske, \& G. Matthews (Eds.), Measures of personality and social psychological constructs (pp. 257-289). San Diego, CA: Elsevier. doi:10.1016/b978-0-12-3869159.00010-3

Norman, H., Marzano, L., Coulson, M., \& Oskis, A. (2018). Effects of mindfulness-based interventions on alexithymia: A systematic review. Evidence Based Mental Health, 22, 3643. doi:10.1136/ebmental-2018-300029

Onur, E., Alkin, T., Sheridan, M. J., \& Wise, T. N. (2013). Alexithymia and emotional intelligence in patients with panic disorder, generalized anxiety disorder and major depressive disorder. Psychiatric Quarterly, 84, 303-311. doi:10.1007/s11126-012-9246-y

Öst, L. (2008). Efficacy of the third wave of behavioral therapies: A systematic review and metaanalysis. Behaviour Research and Therapy, 46, 296-321. doi: 10.1016/j.brat.2007.12.005

Panayiotou, G., Leonidou, C., Constantinou, E., Hart, J., Rinehart, K. L., Sy, J. T., \& Björgvinsson, T. (2015). Do alexithymic individuals avoid their feelings? Experiential avoidance mediates the association between alexithymia, psychosomatic, and depressive symptoms in a community and a clinical sample. Comprehensive Psychiatry, 56, 206-216. doi: 10.1016/j.comppsych.2014.09.006

Parker, J. D. A., Taylor, G. J., \& Bagby, R. M. (1993). Alexithymia and the recognition of facial expressions of emotion. Psychotherapy and Psychosomatics, 59, 197-202. doi:10.1159/000288664

Prkachin, G. C., Casey, C., \& Prkachin, K. M. (2009). Alexithymia and perception of facial expressions of emotion. Personality and Individual Differences, 46, 412-417. doi: 10.1016/j.paid.2008.11.010 
Rendon, K.P. (2006). Understanding alcohol use in college students: A study of mindfulness, selfcompassion and psychological symptoms. Unpublished doctoral dissertation, University of Texas at Austin. Available: https://repositories.lib.utexas.edu/handle/2152/2907

Reniers, R. L., Corcoran, R., Völlm, B. A., Mashru, A., Howard, R., \& Liddle, P. F. (2012). Moral decision-making, ToM, empathy and the default mode network. Biological Psychology, 90, 202-210. doi: 10.1016/j.biopsycho.2012.03.009

Ross, S., Bossis, A., Guss, J., Agin-Liebes, G., Malone, T.,.....\& Schmidt, B.L. (2016). Rapid and sustained symptom reduction following psilocybin treatment for anxiety and depression in patients with life-threatening cancer: A randomized controlled trial. Journal of Psychopharmacology, 30, 1165-1180. doi: 10.1177/0269881116675512

Segal, Z. V., Williams, J. M. G., \& Teasdale, J. D. (2002). Mindfulness- based cognitive therapy for depression: A new approach to preventing relapse. New York: Guilford.

Singer, J. L. (2006). Imagery in psychotherapy. Washington, DC: American Psychological Association.

Spreng, R. N., McKinnon, M. C., Mar, R. A., \& Levine, B. (2009). The Toronto Empathy Questionnaire: Scale development and initial validation of a factor-analytic solution to multiple empathy measures. Journal of Personality Assessment, 91, 62-71. doi: $10.1080 / 00223890802484381$

Stallman, H. M. (2010). Psychological distress in university students: A comparison with general population data. Australian Psychologist, 45, 249-257. doi:10.1080/00050067.2010.482109

Taylor, G. J., Bagby, R. M., \& Parker, J. D. A. (1997). Disorders of affect regulation: Alexithymia in medical and psychiatric illness. Cambridge, UK: Cambridge University Press.

Thorberg, F. A., Young, R. M., Sullivan, K. A., \& Lyvers, M. (2009). Alexithymia and alcohol use disorders: A critical review. Addictive Behaviors, 34, 237-245. doi:

10.1016/j.addbeh.2008.10.016 
Thorberg, F. A., Young, R. M., Sullivan, K. A., \& Lyvers, M. (2011a). Parental bonding and alexithymia: A meta-analysis. European Psychiatry, 26, 187- 193. doi: 10.1016/j.eurpsy.2010.09.010

Thorberg, F.A., Young, R., Sullivan, K.A., Lyvers, M., Connor, J.P. \& Feeney, G.F.X. (2011b). Alexithymia, craving and attachment in a heavy drinking population. Addictive Behaviors, 36, 427-430. doi: 10.1016/j.addbeh.2010.12.016

Thorberg, F. A., Young, R., Sullivan, K. A., Lyvers, M., Hurst, C., .. \& Feeney, G. F. X. (2016). A prospective mediational study on the stability of alexithymia among alcohol-dependent outpatients in Cognitive-Behavioral Therapy. Psychology of Addictive Behaviors, 30, 6472. doi: $10.1037 / \mathrm{adb} 0000135$

Tolmunen, T., Heliste, M., Lehto, S. M., Hintikka, J., Honkalampi, K., \& Kauhanen, J. (2011). Stability of alexithymia in the general population: An 11-year follow-up. Comprehensive Psychiatry, 52, 536-541. doi: 10.1016/j.comppsych.2010.09.007

Vanheule, S., Desmet, M., Meganck, R., \& Bogaerts, S. (2007). Alexithymia and interpersonal problems. Journal of Clinical Psychology, 63, 109-117. doi: 10.1002/jclp.20324

Velde, J. V., Servaas, M. N., Goerlich, K. S., Bruggeman, R., Horton, P., Costafreda, S. G., \& Aleman, A. (2013). Neural correlates of alexithymia: A meta-analysis of emotion processing studies. Neuroscience \& Biobehavioral Reviews, 37, 1774-1785. doi:

10.1016/j.neubiorev.2013.07.008

Wei, M., Liao, K. Y., Ku, T., \& Shaffer, P. A. (2011). Attachment, self-compassion, empathy, and subjective well-being among college students and community adults. Journal of Personality, 79, 191-221. doi: 10.1111/j.1467-6494.2010.00677.x

Zackheim, L. (2007). Alexithymia: The expanding realm of research. Journal of Psychosomatic Research, 63, 345-347. doi: 10.1016/j.jpsychores.2007.08.011 
Table 1

Means, Standard Deviations and Intercorrelations of Study Variables $(N=253)$

\begin{tabular}{|c|c|c|c|c|c|c|}
\hline Variable & $M(S D)$ & 1 & 2 & 3 & 4 & 5 \\
\hline 1. Self-compassion & $2.73(.77)$ & - & & & & \\
\hline 2. Empathy & $48.70(8.24)$ & $.13^{*}$ & - & & & \\
\hline 3. Alexithymia & $50.11(13.18)$ & $-.51 * *$ & $-.40 * *$ & - & & \\
\hline 4. Negative Mood & $20.32(14.19)$ & $-.53 * *$ & -.05 & $.49^{* *}$ & - & \\
\hline 5. Age & $21.57(3.40)$ & .04 & -.01 & .04 & .02 & - \\
\hline 6. Education & $2.48(.65)$ & $.21 *$ & -.05 & -.08 & -.11 & $.66^{* *}$ \\
\hline
\end{tabular}

Note. ${ }^{*} p<.05 . * * p<.01$. 
Table 2

Hierarchical Multiple Regression on Self-Compassion

\begin{tabular}{|c|c|c|c|c|c|}
\hline Predictor & $\Delta R^{2}$ & $\beta$ & $B$ & $S E B$ & $95 \%$ CI for $B$ \\
\hline Step 1 & $.11 * * *$ & & & & \\
\hline Gender & & -.01 & -.54 & 3.08 & {$[-6.61,5.53]$} \\
\hline Medication & & $-.25 * * *$ & -12.84 & 3.09 & {$[-18.92,-6.76]$} \\
\hline Education & & $.24 * * *$ & 7.34 & 1.87 & {$[3.66,11.02]$} \\
\hline Step 2 & $.02 *$ & & & & \\
\hline Gender & & -.04 & -2.14 & 3.15 & {$[-8.34,4.07]$} \\
\hline Medication & & $-.25 * * *$ & -12.90 & 3.07 & {$[-18.94,-6.86]$} \\
\hline Education & & $.24 * * *$ & 7.25 & 1.86 & {$[3.60,10.91]$} \\
\hline Empathy & & $.13^{*}$ & .32 & .15 & {$[.03, .62]$} \\
\hline Step 3 & $.22 * * *$ & & & & \\
\hline Gender & & -.01 & -.45 & 2.74 & {$[-5.85,4.96]$} \\
\hline Medication & & $-.21 * * *$ & -10.93 & 2.67 & {$[-16.12,-5.66]$} \\
\hline Education & & $.20 * * *$ & 6.06 & 1.62 & {$[2.88,9.25]$} \\
\hline Empathy & & -.08 & -.19 & .14 & {$[-.47, .09]$} \\
\hline Alexithymia & & $-.51 * * *$ & -.78 & .09 & {$[-.95,-.61]$} \\
\hline
\end{tabular}

Note. $\mathrm{SE} \mathrm{B}=$ standard error of unstandardized coefficient; $\mathrm{CI}=$ confidence interval.

$* p<.05$. *** $p<.0001$. 
Table 3

Hierarchical Multiple Regression on Negative Mood

\begin{tabular}{llllll}
\hline Predictor & $\Delta R^{2}$ & $\beta$ & $B$ & $S E B$ & $95 \%$ CI for $B$ \\
\hline Step 1 & $.11^{* * *}$ & & & & \\
& & -.03 & -1.17 & 2.17 & {$[-5.45,3.11]$} \\
& & $.31^{* * *}$ & 11.11 & 2.18 & {$[6.82,15.40]$} \\
& Mender & $-.14^{*}$ & -3.10 & 1.32 & {$[-5.70,-.51]$}
\end{tabular}

Step 2

$.22 * * *$

$\begin{array}{llccc}\text { Gender } & -.02 & -.61 & 1.90 & {[-4.35,3.13]} \\ \text { Medication } & .27^{* * *} & 9.90 & 1.91 & {[6.15,13.66]} \\ \text { Education } & -.10 & -2.25 & 1.15 & {[-4.52, .03]} \\ \text { Alexithymia } & .47^{* * *} & .50 & .06 & {[.39, .61]}\end{array}$

Step 3

$.07 * * *$

$\begin{array}{lllll}\text { Gender } & -.03 & -.92 & 1.80 & {[-4.47,2.64]} \\ \text { Medication } & .21^{* * *} & 7.40 & 1.87 & {[3.71,11.08]} \\ \text { Education } & -.04 & -.87 & 1.13 & {[-3.09,1.35]} \\ \text { Alexithymia } & .31 * * * & .34 & .06 & {[.21, .46]} \\ \text { Self-Compassion } & -.32 * * * & -.23 & .04 & {[-.31,-.14]}\end{array}$

Note. $\mathrm{SE} \mathrm{B}=$ standard error of unstandardized coefficient; $\mathrm{CI}=$ confidence interval.

$* p<.05$. *** $p<.0001$. 
Table 4

Bivariate correlations of alexithymia, empathy, and negative mood with SCS subscales $(N=253)$

\begin{tabular}{|c|c|c|c|c|c|c|c|c|}
\hline Variable & 1 & 2 & 3 & 4 & 5 & 6 & 7 & 8 \\
\hline 1. Alexithymia & - & & & & & & & \\
\hline 2. Empathy & $-.40 * *$ & - & & & & & & \\
\hline 3. Negative Mood & $.49 * *$ & -.05 & - & & & & & \\
\hline 4. Self-Kindness & $-.38 * *$ & $.14 *$ & $-.34 * *$ & - & & & & \\
\hline 5. Common Humanity & $-.27 * *$ & $.17^{*}$ & $-.22 * *$ & $.67 * *$ & - & & & \\
\hline 6. Mindfulness & $-.41 * *$ & $.18^{* *}$ & $-.31 * *$ & $.70 * *$ & $.66^{* *}$ & - & & \\
\hline 7. Self-Judgement & $.50 * *$ & -.09 & $.60 * *$ & $-.63 * *$ & $-.37 * *$ & $-.42 * *$ & - & \\
\hline 8. Isolation & $.44 * *$ & -.06 & $.54 * *$ & $-.55 * *$ & $-.46 * *$ & $-.52 * *$ & $.75 * *$ & - \\
\hline 9. Overidentification & $.43^{* *}$ & .01 & $.52 * *$ & $-.48 * *$ & $-.35 * *$ & $-.55^{* *}$ & $.71 * *$ & $.75^{* *}$ \\
\hline
\end{tabular}

Note. ${ }^{*} p<.05 . * * p<.01$. 
Table 5

Hierarchical Multiple Regression on Negative Mood using SCS subscales

\begin{tabular}{|c|c|c|c|c|c|}
\hline Predictor & $\Delta R^{2}$ & $\beta$ & $B$ & $S E B$ & $95 \% \mathrm{CI}$ for $B$ \\
\hline Step 1 & $.11 * * *$ & & & & \\
\hline Gender & & -.03 & -1.17 & 2.17 & {$[-5.45,3.11]$} \\
\hline Medication & & $.31 * * *$ & 11.11 & 2.18 & {$[6.82,15.40]$} \\
\hline Education & & $-.14 *$ & -3.10 & 1.32 & {$[-5.70,-.51]$} \\
\hline
\end{tabular}

Step 2

$.22 * * *$

Gender

Medication

Education

Alexithymia

$$
-.02
$$$$
.27 * * *
$$

$-.10$

$.47 * * *$

$14 * * *$

Step 3

$.14 * * *$

$\begin{array}{llccc}\text { Gender } & -.02 & -.65 & 1.76 & {[-4.13,2.82]} \\ \text { Medication } & .19^{* * *} & 6.93 & 1.77 & {[3.43,10.43]} \\ \text { Education } & -.05 & -1.09 & 1.11 & {[-3.28,1.10]} \\ \text { Alexithymia } & .26^{* * *} & .28 & .06 & {[.16, .40]} \\ \text { Self-Kindness } & .12 & 1.85 & 1.34 & {[-.87,4.56]} \\ \text { Common Humanity } & .02 & .34 & 1.06 & {[-1.74,2.43]} \\ \text { Mindfulness } & .00 & -.01 & 1.24 & {[-2.45,2.44]} \\ \text { Self-Judgement } & .35^{* * *} & 5.08 & 1.33 & {[2.46,7.70]} \\ \text { Isolation } & .11 & 1.52 & 1.16 & {[-.76,3.81]} \\ \text { Overidentification } & .10 & 1.37 & 1.18 & {[-.96,3.71]}\end{array}$

Note. $\mathrm{SE} \mathrm{B}=$ standard error of unstandardized coefficient; $\mathrm{CI}=$ confidence interval. $* p<.05 .{ }^{* * *} p<.0001$. 